\title{
Apropiación, accesibilidad y paisaje urbano en el espacio público del Centro Histórico de San Luis Potosí, México
}

\begin{abstract}
Adrián Moreno Mata Cristina Beltrán Moncada ${ }^{1}$

División de Vinculación Universitaria

Primera versión recibida: 6 de abril de 2017 • Última versión recibida: 16 de junio de 2017
\end{abstract}

\section{Resumen}

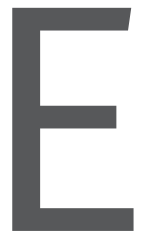

n este texto se aborda la apropiación del espacio público por parte del comercio ambulante en el Centro Histórico de la ciudad de San Luis Potosí, México. Se exploran algunas de las consecuencias de este fenómeno y, en particular, su impacto sobre el paisaje urbano y el patrimonio histórico-cultural. La perspectiva que se adopta considera tres categorías analíticas que, a su vez, se traducen de manera operativa en el enfoque metodológico: i) Accesibilidad; ii) Percepción del usuario; y iii) Cualidades espaciales.

1 Universidad Autónoma de San Luis Potosí. adrian.moreno@uaslp.mx, cristinabelmcda@ gmail.com

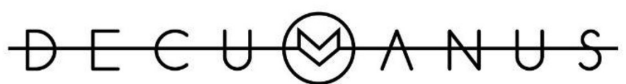

REVISTA INTERDISCIPLINARIA SOBRE ESTUDIOS URBANOS
Las fuentes de información utilizadas se derivaron de la revisión bibliográfica efectuada, información proveniente de censos económicos, medios, y cartografía empleada para ubicar espacialmente el problema de investigación. También se aprovecharon resultados preliminares de una encuesta aplicada a actores clave locales. En el primer apartado, se describen algunos conceptos básicos para abordar el problema; luego se presentan algunos antecedentes históricos del comercio ambulante en la ciudad y se describe su dinámica actual, su distribución espacial en el Centro Histórico y la principal área de influencia que ocupa. Más adelante, se analiza la postura de las autoridades frente al problema, así como las opiniones de los actores principales que intervienen en el fenómeno. El apartado final presenta la interpretación de los autores respecto a las complejas relaciones entre el fenómeno de apropiación del espacio urbano, la accesibilidad al espacio público y la estética de la ciudad. Se 
discute, de manera breve, sobre las implicaciones actuales y futuras que tendría este problema en el caso de estudio, y algunas reflexiones relacionadas con las medidas que en materia de política urbana, se podrían implementar para enfrentarlo o mitigarlo.

Palabras clave: apropiación del espacio público; accesibilidad al Centro Histórico; estética urbana.

\section{Abstract}

The document analyses the phenomenon of appropriation of the public space by the itinerant commerce in the Historical Center of the city of San Luis Potosí, Mexico, and its relation with three integrated problems: loss of accessibility, detriment of urban landscape, and historical-cultural heritage damage. The perspective adopted considers three basic concepts that, in turn, became in operational categories into the methodological approach: i) Accessibility; ii) User perception; and iii) Spatial qualities. The sources of information used were derived from the literature review, information from economic censuses, media, and cartography used to locate the research problem. Preliminary results of a survey of local key players were also used by a Quality Data Analysis (Atlas.ti software). The first section describes some basic concepts to address the problem. Then some historical antecedents of the itinerant commerce in the city are presented, and its current dynamics are described that includes the spatial distribution of itinerant commerce in the Historical Center and the main area of influence that occupies-. Later section presents the position of key players - citizens, street merchants, and authorities- on the problem and the opinions of the main actors involved in the research problem. The final section includes some aspects: the authors' interpretation of the complex relationships between the phenomenon of appropriation of urban space, accessibility to the public space, and the aesthetics of the inner city. It briefly discusses the current and future implications of this problem in the case study and some reflections on measures that could be implemented in urban policy to address or mitigate it.

Keywords: appropriation of public space; accessibility to the Historical Center; urban aesthetics.

\section{Sumario}

1) Introducción. 2) Aspectos teórico-metodológicos. 3) Resultados de la investigación. 4) Conclusiones y recomendaciones. 5) Bibliografia

\section{Introducción}

Durante la segunda mitad del siglo pasado y en lo que va del siglo XXI, la producción y el funcionamiento del espacio en las ciudades latinoamericanas, se han vuelto cada vez más complejos, a partir de la yuxtaposición de diversos modelos socioespaciales intraurbanos. La interacción de procesos de concentración-centralidad/dispersión-periferia genera una estructura urbana basada en nuevos polos de centralidad y flujos de movilidad que tienden cada vez más a la dispersión metropolitana, fragmentación espacial, terciarización de las

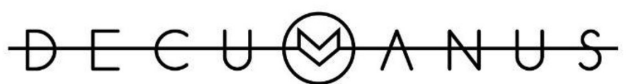

REVISTA INTERDISCIPLINARIA SOBRE ESTUDIOS URBANOS 
actividades económicas y promoción de grandes megaproyectos urbanos o residenciales. Las relaciones entre ciudad y sus áreas centrales, y entre espacio y sociedad también se modifican, transformando de manera radical prácticas tradicionales de carácter simbólico en las que la vida social, política, cultural y religiosa estaba fuertemente centrada.

Entre las interpretaciones de corte académico que exploran el fenómeno de la informalidad en América Latina, se encuentran aquellas que, por un lado, realizan el análisis basadas en estudios macroeconómicos, desde los cuales, de manera general, se aborda el tema de la economía informal (De Soto, \& Portes, 1995); y, por otro lado, trabajos que sitúan el problema del comercio informal a partir de estudios de caso, como un aspecto general que afecta a las llamadas "ciudades duales", relacionándolo con temas más amplios como la configuración de periferias urbanas, ilegalidad y legitimidad de asentamientos informales, vivienda popular y medios alternativos de transporte. En esta segunda corriente de análisis, las políticas locales y las condiciones económicas y sociales de cada ciudad son aspectos que imprimen particularidades al fenómeno del comercio ambulante (Galeano-Rojas, 2007; Portes, Roberts, \& Grimson, 2005; Valdivieso, 2003; Veleda, 2001).

Respecto a las definiciones sobre el comercio ambulante, se encuentran aquellas que lo distinguen del comercio informal, del comercio itinerante y del comercio callejero. Para López (2015), el comercio informal se define como aquel intercambio económico que se realiza de manera irregular y oculto; irregular, porque no sigue los procesos fiscales y de permisos requeridos por las autoridades para ejercer esa actividad, y oculto, porque es precisamente esa irregularidad la que provoca que esos intercambios sean dificiles de cuantificar para su estudio. Según diversas definiciones institucionales, el comercio ambulante o ambulantaje se define como "... agrupaciones comerciales que ejercen el comercio de productos generalizados en la vía pública o terrenos (sitio fijo) ya sea o no propiedad del DDF, y que carecen de la más indispensable infraestructura para su funcionamiento adecuado" (González, 2002, p. 36). El artículo 135 de la Ley de Hacienda del Distrito Federal define al comerciante ambulante como la persona que usa las vías públicas para llevar a cabo actividades mercantiles de cualquier tipo, ya sean en puestos fijos, semifijos o en forma ambulante. No obstante, en estricto sentido, el término ambulantaje se relaciona con el comercio que se traslada de un lado a otro sin establecerse en un punto fijo, que existe y causa problemas menores; de ahí su similitud con el comercio itinerante, que, según Castillo (2003), sería aquel que se lleva a cabo fuera de establecimientos comerciales permanentes con el empleo de instalaciones desmontables, transportables o móviles. Todas estas definiciones dan cuenta de la diversidad de interpretaciones sobre este fenómeno, de la complejidad de sus causas y efectos, y de las distintas subdivisiones o perspectivas desde las cuales se puede distinguir.

En el caso de México, los orígenes del comercio ambulante o itinerante,

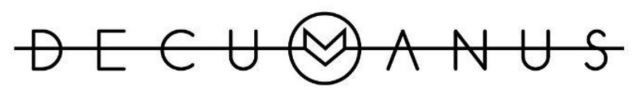

REVISTA INTERDISCIPLINARIA SOBRE ESTUDIOS URBANOS
Núm. 2. Vol. 2. Octubre 2016-Octubre 2017. Instituto de Arquitectura, Diseño y Arte.

Universidad Autónoma de Ciudad Juárez. ISSN: 2448-900X 
según diversos autores, se remonta a la época prehispánica y, en particular, al tianquiztli, lugar donde se practicaba el ejercicio del trueque y el arte de traficar o pochtecayolt (Castillo, 2003, p. 23). En ese lugar concurrían diversos vendedores, especializados y no especializados, a comerciar una amplia gama de mercaderías, colocadas y ordenadas de acuerdo con el producto ofrecido. En etapas posteriores, esta modalidad de comercio derivó en la plaza-mercado, el corredor comercial y el mercado público (Castillo, 2003, p. 23). Sin embargo, paralelo a estas distintas formas históricas de mercado en México, coexistió con ellas lo que se conoce como comercio ambulante, que desbordaba los límites espaciales y giros comerciales asociados al comercio establecido en los mercados públicos y corredores comerciales, concentrándose en plazas y espacios públicos, y generando desde entonces serios problemas (González, 2002).

A lo largo de la primera mitad del siglo xx, los componentes asociados al comercio adyacente a la plaza-mercado y a corredores comerciales, tendrian otras transformaciones que darían la configuración actual a lo que se conoce como comercio ambulante. Durante los años sesenta y setenta, asociado al desarrollo de la economía informal y a transformaciones importantes del mercado de trabajo ocurridas a nivel internacional, surge el término sector informal y en diversos países el comercio ambulante pasó a designarse como comercio informal (OIT, 1991). En México, a partir de 1992, se le denominó comercio en la vía pública (Castillo, 2003, p. 93).

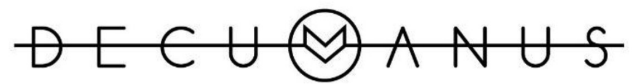

REVISTA INTERDISCIPLINARIA SOBRE ESTUDIOS URBANOS
En la actualidad, el fenómeno del comercio ambulante se inscribe en las transformaciones estructurales y morfológicas que sufren numerosas ciudades mexicanas relacionadas con cambios en el modelo de ciudad-pérdida de la importancia de las áreas centrales, paso de un modelo monocéntrico a otro policéntrico y de la ciudad compacta a otra dispersa y fragmentada (Moreno, 2010), entre otros aspectos. La expansión urbana periférica y el vaciamiento y abandono de las áreas urbanas centrales, que caracterizan las tendencias de desarrollo urbano de las grandes y medianas metrópolis del país, han generado diversas consecuencias sociales, económicas y espaciales: i) Despoblamiento y deterioro de las áreas centrales con el consecuente desperdicio o subutilización de servicios, infraestructura y equipamiento social acumulados; ii) Hábitat deteriorado en el que aún se asientan familias de escasos recursos y donde se observa el incremento de la inseguridad y la delincuencia; iii) Presencia de comercio ambulante, sin regulación y desordenado, y de disputas crecientes por el espacio público entre distintos agentes sociales; y iv) Obsolescencia y descuido del patrimonio histórico-cultural (Moreno, 2015).

En este contexto el trabajo analiza el fenómeno de la apropiación del espacio público por el comercio ambulante en el Centro Histórico de la ciudad de San Luis Potosí, México, y su relación con tres problemas que se articulan: i) Pérdida de accesibilidad; ii) Deterioro del paisaje urbano; y iii) Decadencia del patrimonio histórico-cultural. El enfoque adoptado considera tres conceptos básicos, que en su momento 
se convierten en categorías analíticas que orientan la estrategia metodológica: i) Accesibilidad; ii) Percepción del usuario; y iii) Cualidades espaciales. Las fuentes de información utilizadas incluyeron la revisión de literatura, censos económicos y de población y vivienda, y cartografía para delimitar el área de estudio. También se emplearon los resultados preliminares de una entrevista aplicada a actores clave (comerciantes ambulantes, funcionarios y transeúntes), que posteriormente se procesaron mediante el programa de análisis cualitativo de datos Atlas.ti (Konopásek, 2008).

\section{Aspectos teórico-metodológicos}

Como señala Ramírez (2015), siguiendo a Lefebvre (1976):

...un punto de partida para conocer la ciudad es pensarla como espacio social y simbólico percibido, vivido y apropiado por individuos y grupos diferentes, que tienen un papel activo en la definición del orden urbano y en la producción de la forma, la estructura y las actividades socioeconómicas y político-culturales (pp. 7-8).

Agrega esta autora que, en la construcción social y simbólica de la ciudad, el espacio público es un elemento fundamental del orden urbano que, en su relación con el espacio privado, expresa la manera como los habitantes usan y tienen acceso a los recursos sociales, y la relación entre estos, ciudad e instituciones. Las tensiones en esta relación tienen que ver, entre otras cuestiones, con la tendencia a la subordinación de lo público a lo privado y con el predominio de lo privado como interés general, lo que altera el sentido colectivo de lo público como espacio de todos (Ramírez, 2013, p. 8).

Ahora bien, desde la perspectiva de la accesibilidad -tanto espacial como social-, el significado del espacio o la esfera públicos se asocia a menudo con el concepto clásico de los ciudadanos de reunirse para discutir las cuestiones de interés público, para producir un debate público abierto y libre o para discutir sobre preocupaciones públicas. Encontramos esta definición de espacio público en las obras de Arendt (1958) y Habermas (1989), los dos filósofos sociales más influyentes que formularon la idea de esfera pública.

Tratándose de la ciudad, el espacio público hace referencia a dos dimensiones: i): Espacio físico, que remite a los sitios identificados de encuentro entre la gente, de confluencia e intercambio (plazas, calles, centros de diversión y de reunión); y ii) Espacio político, que en ocasiones coincide también con ser un espacio físico (Congreso, cámaras, instituciones, etcétera), pero que tiene la cualidad, en general, de ser un espacio desterritorializado, definido principalmente por la circunstancia de constituirse a partir de la acción mancomunada de grupos e individuos (Arditi, 1995).

Otro enfoque asocia al espacio público con el concepto de "sociabilidad", es decir, la posibilidad del encuentro y comunicación de los extraños. Este enfoque es más cultural que político y suele estar vinculado a la obra de autores como Sennett (2011), quien comprende el espacio público como

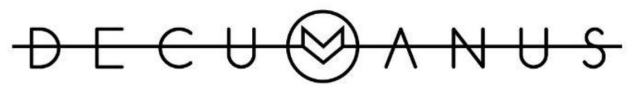

REVISTA INTERDISCIPLINARIA SOBRE ESTUDIOS URBANOS 
un lugar estático donde los extraños se reúnen y permanecen por un tiempo. Esto hace del espacio público una especie de escenario para efectuar determinadas interacciones sociales.

Por su parte, Bauman (1998), a través del concepto clásico de espacio público, nos remite a dos posturas antagónicas, que en la práctica se traducen en tendencias contemporáneas confrontadas: por un lado, la posibilidad y el derecho a acceder libremente al espacio público (Borja, 2012) y a usarlo para un propósito común (Zukin, 1995), donde el espacio es incluyente y accesible para todos: un área de confluencia de individuos, comunicación y expresión. Por el otro, la privatización, dominación y apropiación del espacio por parte de ciertos sectores de la sociedad y de la economía urbanas (gobierno, empresas, grupos de poder, comerciantes ambulantes, etcétera). El espacio público se convierte, entonces, en el escenario de debates, polémicas y conflictos entre grupos, cada uno con intereses, prácticas y demandas particulares (Ramírez, 2009) y con discursos e identidades diferentes.

Al respecto, de acuerdo con Lefebvre (1973), la percepción del espacio público que tiene el usuario parte del significado de la relación entre ambos componentes (lugar y usuario) y la representación misma del lugar. De acuerdo con este autor, el espacio público puede representarse a través de diversas dimensiones: "Se presenta como algo vivo, dinámico y el cual se produce e instituye no sólo desde la normatividad del Estado, pero también desde las vivencias (imágenes, símbolos) cotidianas y modos que tie- ne el ciudadano común de practicarlo y observarlo" (Lefebvre, 1973, p. 15).

Esta dimensión del espacio público es definida por De Certeau (1999) como la significación del lugar, que se traduce en apropiaciones que recomponen el espacio propuesto por el entorno en la medida en la que las colectividades lo hacen parte de ellas, siendo esta dinámica parte de la práctica cultural (Harvey, 1989). Ante esto, Borja y Muxí (2000) señalan que

...el espacio público es un producto material en relación con otros elementos materiales, entre ellos los hombres, los cuales contraen determinadas relaciones sociales, que dan al espacio (y a los otros elementos de la combinación) una forma, una función, una significación social (p. 15).

Estos autores dejan en claro que, desde esta concepción, el espacio otorga una forma y una función a los sujetos que lo transitan, que lo ocupan y que se lo apropian.

A esta reflexión, se le puede agregar que las causas y las consecuencias de las nuevas formas de transformación (apropiación) y territorialización espacial, se deben a que los procesos y modos en los que se ocupa actualmente el espacio público, han cambiado gradualmente, con el fin de otorgarle una nueva significación, ligada más bien con las nociones de límites, fronteras y porosidad, y también con las de identidad, interacciones, redes, movimientos y flujos (Mongin, 2006).

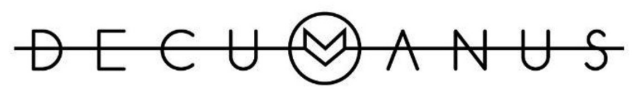

REVISTA INTERDISCIPLINARIA SOBRE ESTUDIOS URBANOS
Núm. 2. Vol. 2. Octubre 2016-Octubre 2017. Instituto de Arquitectura, Diseño y Arte.

Universidad Autónoma de Ciudad Juárez. ISSN: 2448-900X 
Espacio público, paisaje urbano y cualidades espaciales

En la actualidad, se observa una marcada tendencia a la estetización de todos los aspectos de la vida social. Como planteaba Baudrillard (1980): “... todo lo que nos rodea requiere estar diseñado y estetizado". En cuanto al paisaje urbano y la cultura pública de la ciudad, esta tendencia se expresa en tres aspectos: i) Predominio de la industria cultural y creativa, y su papel en la producción del espacio urbano; ii) Aplicación de los ideales modernistas de la planificación urbana y el diseño; y iii) Emergencia de "tácticas de resistencia" a la estetización con la consecuente reapropiación del espacio urbano (citado en Gane, 1993).

La globalización económica y social impulsa el desarrollo de la industria cultural y creativa urbana, a partir de la adopción de patrones, estilos y preferencias estéticas acotados por normas preestablecidas y que convierten a las ciudades en centros de moda, cultura y "gusto" artístico. En consecuencia, la lógica dominante de estetización del espacio urbano implica que solo unas pocas formas particulares de estética son posibles y tienen valor universal (Zukin, 1995). Por ejemplo, las políticas y programas de renovación urbana, de gentrificación, el "arreglo" estético de las principales vialidades, la organización de festivales artísticos y, en general, las acciones de cultura urbana impulsadas por los gobiernos locales, se sitúan en esta tendencia. También lo hacen la regulación de los espacios públicos, la limpieza o sanidad de los centros históricos, la división funcional o zonificación de usos del suelo y espacios, que contribuyen a la estetización de las ciudades modernas y a hacer de ellas centros culturales. Al mismo tiempo, esas acciones impulsan una idea generalizada, un "modelo estético" de ciudad que las políticas de promoción turística (por ejemplo, en México el Programa "Pueblos Mági$\cos ^{\prime \prime}$ y y los gestores de la ciudad imponen, clasificando el desorden y la diversidad como aspectos inaceptables en la estética de la ciudad.

El comercio ambulante y el conflicto con la sociedad

El debate académico y social acerca de la dinámica actual de los centros históricos, abarca, entre múltiples factores, la presencia del comercio ambulante en áreas centrales de las ciudades y los efectos que se generan ante la eventual apropiación que esta actividad económica realiza sobre el espacio urbano, así como los conflictos sociales que ello provoca: entorpecimiento de la accesibilidad y la movilidad, deterioro de la imagen urbana, afectación del comercio formal $y$ el turismo cultural, $y$, en general, el funcionamiento de la ciudad.

Se trata de conflictos que se producen entre comerciantes en la vía pública, comerciantes establecidos, comités vecinales, delegaciones políticas y funcionarios, y ciudadanos en general. Podría añadirse que el conflicto se extiende hacia otras cuestiones, como la discusión entre la separación de lo público y lo privado, la expresión de relaciones de poder presentes en la sociedad mediante las cuales unos grupos excluyen a otros, y hacia otros fenómenos, como el derecho a la ciu-

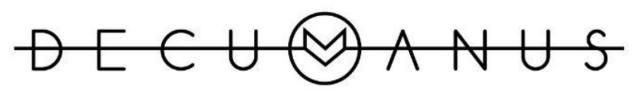

REVISTA INTERDISCIPLINARIA SOBRE ESTUDIOS URBANOS
Núm. 2. Vol. 2. Octubre 2016-Octubre 2017. Instituto de Arquitectura, Diseño y Arte.

Universidad Autónoma de Ciudad Juárez. ISSN: 2448-900X 
dad, que implica las dificultades para hacer compatible el goce de un conjunto de derechos entre sí, de ciertos actores sociales -como es el caso de los comerciantes informales- y del resto de los ciudadanos.

La presencia de estos conflictos, ha abierto una veta importante de investigación acerca del tema, donde una cuestión central es preguntarse respecto a las relaciones entre el espacio urbano y el comercio en la vía pública (Coulomb, 2010; Ramírez, 2013).

Marco analítico y enfoque metodológico de la investigación

El marco analítico de la investigación, se construyó, al igual que los aspectos teórico-conceptuales, con base en una revisión bibliográfica acerca del estado de la cuestión respecto al objeto de estudio. A partir de esas lecturas, se identificaron tres categorias operativas: i) Accesibilidad (Augusto, \& Flórez, 2005); ii) Percepción del usuario (Castillo, 1996); y iii) Cualidades espaciales (Schjetnan, 2008), cada una de ellas con sus respectivos componentes (véase figura 1).

En referencia a la categoría de Accesibilidad, es importante señalar su conexión con otros conceptos, como la centralidad y la movilidad. Siguiendo a Carrión (2007):

...la centralidad da paso a una nueva expresión caracterizada por el reemplazo del espacio de los lugares por el de los flujos, senderos y tránsitos, con lo cual prevalece el movimiento de las personas, la información y los recursos. Se pasa de un centro que se construye sobre la base del encuentro hacia otro que significa tránsito, flujo, movilidad.

No obstante, de acuerdo con Jirón et al. (2010), la accesibilidad involucra no solo aproximarse al transporte, sino también a la localización, reparto y distribución de ciertas actividades clave -como es el caso del comercio, en general, y del comercio informal, en particular.

Ambas posturas, la que ubica a la movilidad espacial y a los flujos a escala urbana como aspectos inseparables de la accesibilidad, y la que considera los efectos espaciales que tiene el fenómeno del ambulantaje con su presencia en el lugar -el Centro Histórico-, se consideran en el abordaje metodológico. En el primer caso, se elaboran la descripción y el análisis de la relación entre los sistemas de movilidad y transporte a escala urbana, la dinámica de accesibilidad al Centro Histórico y la forma en la que la actividad del comercio informal impacta los flujos de movilidad y la propia estructura de la ciudad. En el segundo caso, la accesibilidad se analiza en relación con la imagen urbana, el espacio y el individuo, tomando en cuenta los factores que influyen dentro del paisaje urbano y los diversos efectos que tiene el comercio informal en el Centro Histórico.

La información utilizada incluyó datos y cartografía sobre los flujos más importantes de la movilidad y la accesibilidad al Centro Histórico, su relación con el área de influencia del comercio informal $\mathrm{y}$, de manera concreta respecto al área estudiada, el número específico de usuarios frecuentes en el lugar, destacando su opinión sobre

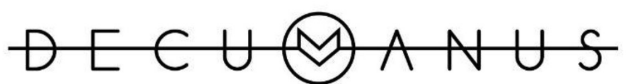

REVISTA INTERDISCIPLINARIA SOBRE ESTUDIOS URBANOS
Núm. 2. Vol. 2. Octubre 2016-Octubre 2017. Instituto de Arquitectura, Diseño y Arte.

Universidad Autónoma de Ciudad Juárez. ISSN: 2448-900X 
Figura 1. Categorías operativas: Accesibilidad, Percepción del usuario y Cualidades espaciales.

\begin{tabular}{|c|c|c|}
\hline Componente & Descripción Explicativa & Categorías Analíticas \\
\hline 1. Espacial & Relaciones del individuo con el medio & \multirow{5}{*}{ Accesibilidad } \\
\hline 2. psicológica-social & $\begin{array}{l}\text { Lazos individuales con otras personas } \\
\text { y organizaciones }\end{array}$ & \\
\hline 3.Seguridad & $\begin{array}{l}\text { las condiciones a desarrollarse las } \\
\text { prácticas accesibles deben ser } \\
\text { compatibles con la configuración de los } \\
\text { entornos construidos. }\end{array}$ & \\
\hline 4.Normalización & $\begin{array}{l}\text { Instrumento reglamentario elemental en } \\
\text { el desarrollo del espacio público }\end{array}$ & \\
\hline 5. Enclaves, sitios no situados & $\begin{array}{l}\text { Elementos organizados por las vías } \\
\text { circulatorias, fuera de un orden }\end{array}$ & \\
\hline 6. Público o privado & $\begin{array}{l}\text { la posibilidad de hacer o no uso de este } \\
\text { espacio. }\end{array}$ & \multirow{4}{*}{ Percepción } \\
\hline 7. Individual & $\begin{array}{l}\text { La diferencia de opinión acerca del E. } \\
\text { P. difiere de las categorías por sexo y } \\
\text { edad. }\end{array}$ & \\
\hline 8. Mental & $\begin{array}{l}\text { La imagen mental contiene partes de } \\
\text { imaginación y experiencias }\end{array}$ & \\
\hline 9. Afectivo-sensorial & $\begin{array}{l}\text { La imagen es atribuida a los } \\
\text { sentimientos y observación del lugar. }\end{array}$ & \\
\hline 10. Infraestructura & $\begin{array}{l}\text { Tipos de elementos de infraestructura } \\
\text { que se encuentran en el lugar (luz, } \\
\text { drenaje, etc.) y condiciones en las que } \\
\text { se encuentra. }\end{array}$ & \multirow{3}{*}{ Cualidades espaciales } \\
\hline 11. Mobiliario urbano & $\begin{array}{l}\text { Elementos de mobiliario urbano que se } \\
\text { encuentran en el lugar y sus } \\
\text { condiciones. }\end{array}$ & \\
\hline 12. Vegetación & $\begin{array}{l}\text { Tipos de vegetación que existen en el } \\
\text { lugar, como arbustos o elementos de } \\
\text { ornato y las condiciones en las que se } \\
\text { encuentran }\end{array}$ & \\
\hline
\end{tabular}

Fuente: Beltrán (2017) con base en Linares (2010) y Fuentes y Formoso (2000).

aspectos clave que afectan la estructura urbana.

La percepción del usuario en esta investigación, se refiere a un hecho principalmente cognitivo, producido a partir de un organismo controlado por la excitación sensorial. Por extensión, y especialmente en el ser humano, este proceso puede estar influido poderosamente por factores sociales, personales y ambientales (Castillo, 1996). En consecuencia, para esta categoría se analizaron cuatro componentes dentro del margen de percepción, los cuales intervienen en la relación entre la imagen urbana, el individuo y el entorno que lo rodea: i) Público o privado (posibilidad de hacer uso o no de este espacio); ii) Individual (diferencia de opiniones acerca del espacio público; se clasifica según sexo y edad); iii) Mental (imagen que contiene partes derivadas de la imaginación y experiencias históricas o personales); y iv) Afectivo-sensorial (se atribuye a la imagen que generan los sentimientos y la observación del lugar). La información básica para analizar esta ca-

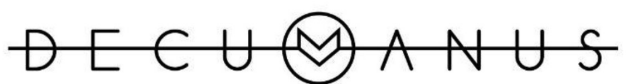

REVISTA INTERDISCIPLINARIA SOBRE ESTUDIOS URBANOS 
tegoría, provino principalmente de las entrevistas de carácter personal aplicadas a usuarios del espacio público en el Centro Histórico de la ciudad de San Luis Potosí. A través de esa técnica de análisis, los usuarios expresaron su percepción del espacio público en cuanto a si se sentían identificados con él, si les proporcionaba seguridad para transitar en él y, en síntesis, si existía cierto grado de apropiación o no de dicho espacio.

Como cualidades espaciales, se consideraron los elementos de mobiliario, equipamiento e infraestructura urbanos localizados en el espacio público, que tienen cierta utilidad para los ciudadanos, que son visibles e importantes para la imagen urbana. Los principales componentes analizados fueron la infraestructura urbana (iluminación, drenaje, etcétera) y las condiciones en las que esta se encuentra (buenas condiciones, desuso o malas condiciones; riesgo para el usuario, etcétera). También se consideró el mobiliario urbano: disponibilidad y condiciones; visibilidad y legibilidad; y elementos distractores u obstáculos a la percepción (como podría ser el caso de las instalaciones para locatarios ambulantes). Finalmente, se incluyó la existencia y tipos de vegetación (árboles o plantas arbustivas y de ornamento; condiciones en las que se encuentran, etcétera) y su expresión (paisaje sano, fértil o lo contrario; estado y uso). El análisis de esta categoría depende, en gran parte, de la percepción de los usuarios, la cual se captó a través de la entrevista aplicada.

A partir de las categorías mencionadas, la información se recopiló a través de una entrevista aplicada en
2016 a actores clave respecto al tema de la apropiación del espacio público por parte del comercio ambulante, y se ordenó y clasificó de manera preliminar en función de la opinión individual $-\mathrm{y}$, por tanto, de la postura- en relación con los problemas vinculados con la apropiación del espacio en el Centro Histórico de la ciudad de San Luis Potosí por parte de los grupos de comerciantes ambulantes. Los actores clave entrevistados incluyeron servidores públicos encargados de la supervisión y asignación de lugares donde se sitúa el comercio ambulante, ciudadanos en general y los propios vendedores ambulantes. Las entrevistas se llevaron a cabo en distintos puntos del área de influencia del comercio ambulante en el Centro Histórico de la ciudad de San Luis Potosí. El tamaño de la muestra fue de cien entrevistas en donde participaron cincuenta transeúntes, treinta comerciantes ambulantes y veinte servidores públicos.

Las preguntas generales que se plantean en la entrevista, se corresponden con las interrogantes propias de la investigación: ¿qué factores urbanos causan la apropiación del espacio público por parte del comercio informal en el Centro Histórico?, ¿cuáles son las consecuencias espaciales y sociales de la presencia del comercio informal dentro del espacio público en el Centro Histórico?, ¿qué estrategias o criterios de diseño urbano permitirán enfrentar o mitigar este fenómeno?

El objetivo de las entrevistas fue dar respuesta a estas interrogantes, a través de la opinión de tres tipos de actores participantes: i) Personas que laboran en cargos públicos con

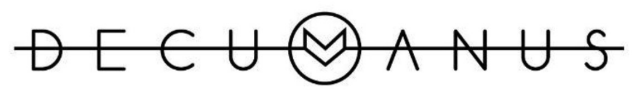

REVISTA INTERDISCIPLINARIA SOBRE ESTUDIOS URBANOS
Núm. 2. Vol. 2. Octubre 2016-Octubre 2017. Instituto de Arquitectura, Diseño y Arte.

Universidad Autónoma de Ciudad Juárez. ISSN: 2448-900X 
competencia en la economía local; ii) Comerciantes formales e informales; y iii) Algunos consumidores de este comercio informal. Se elaboró una entrevista específica para cada tipo de actor y cada tipo de entrevista incluyó un número variable de preguntas: para el ciudadano en general, siete; para el servidor público, cinco; y para el comerciante ambulante, diez. Los factores analizados en las entrevistas (Accesibilidad, Percepción del usuario y Cualidades espaciales), se desglosaron según la posición en el empleo de los entrevistados, así como la frecuencia de visita al sitio. Al ser de carácter individual, las respuestas varian en cada una de las personas entrevistadas. No obstante, fueron de gran utilidad para responder a las interrogantes planteadas.

Por ejemplo, en el tema de Accesibilidad, a los comerciantes ambulantes se les preguntó: ¿cree usted que su puesto o espacio comercial genera algún problema con la circulación de los peatones? En el tema de Percepción del usuario, una de las interrogantes planteadas a los servidores públicos fue: ¿qué consecuencias tiene el comercio informal con respecto a la imagen urbana de la ciudad, específicamente en el Centro Histórico? (seguridad, ecología y salubridad). En el tema de Cualidades espaciales, se incluyeron preguntas como: Mencione qué elementos físicos observa en el lugar que no pertenezcan al comercio informal (rampas, teléfonos públicos y señalética).

Como parte de la estrategia metodológica, los testimonios obtenidos en las entrevistas se clasificaron y analizaron en una etapa posterior utilizando un software para el análisis cualitativo de datos (QDA, por sus siglas en inglés) denominado Atlas.ti (Konopásek, 2008), el cual funciona como procesador de textos y datos multimedia (en este caso, fotografías y videos), que es compatible con el tipo de investigación efectuada y los objetivos planteados.

\section{Resultados de la investigación}

La zona metropolitana de la ciudad de San Luis Potosí, se ubica en la región centro-occidente de México. El Centro Histórico comprende una superficie de 51.64 ha. El área de influencia del comercio informal abarca gran parte del perímetro oficial del Centro Histórico (HSLP, 2007). El área donde se ubica de manera predominante el comerciante ambulante del Centro Histórico, abarca una superficie de 10 ha. Comprende las inmediaciones de los mercados República e Hidalgo, al norte del área central; un corredor peatonal entre ambas instalaciones; parte del corredor urbano Eje Vial; el corredor peatonal que conecta a estos puntos con el jardín de San Francisco, así como el sector poniente de la alameda Juan Sarabia (véase figura 2).

La zona de estudio se ubica sobre el corredor urbano Eje Vial, entre las calles de Reforma e Insurgentes. Este lugar padece una seria problemática, que se refleja tanto a nivel sociodemográfico como económico y urbano. Uno de los problemas más agudos, es la presencia constante de comercio ambulante en un área importante del casco antiguo.

Uno de los impactos que genera, es el gran número de puestos que se han

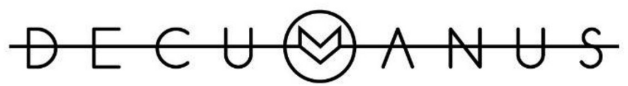

REVISTA INTERDISCIPLINARIA SOBRE ESTUDIOS URBANOS 
Figura 2. Ubicación del área de estudio (ZMSLP; límites de los perímetros oficiales de conservación del Centro Histórico; área de influencia del comercio ambulante; localización de la zona de estudio).

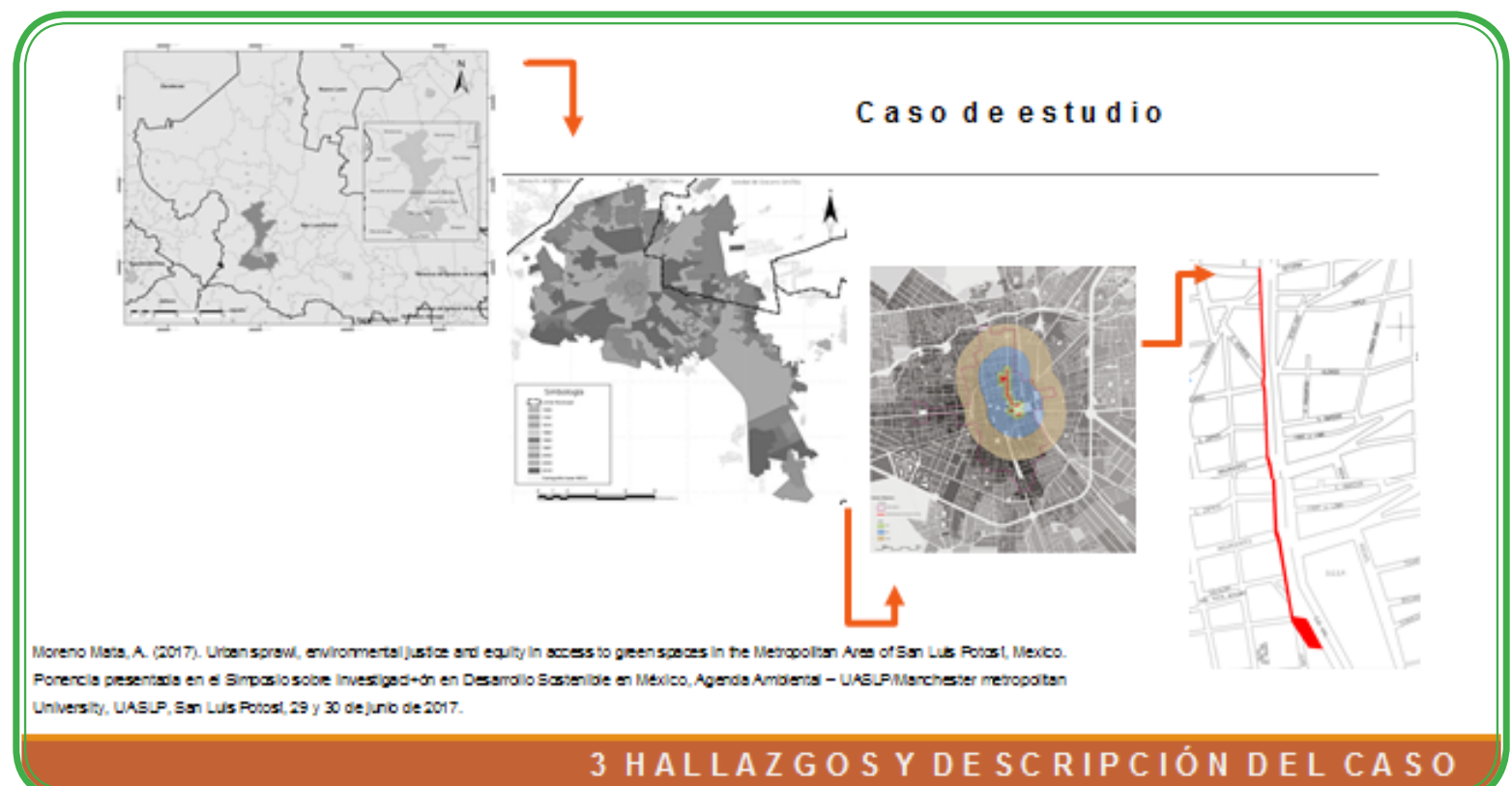

Fuente: Beltrán (2017) con base en el INAH (1990; 2002).

instalado en el núcleo histórico en la etapa reciente y que alteran la imagen urbana del lugar, además de su funcionamiento. Al ser un centro colonial antiguo que concentra el patrimonio arquitectónico y artístico, el área de estudio constituye un punto de atracción turística y comercial de carácter regional, con flujos importantes de distintos tipos de usuarios: cotidianos y esporádicos, locales y foráneos, turistas y prestadores de servicios, empleados de actividades diversas (gobierno, comercio y servicios), etcétera.

En la tabla 1, se muestra el número de comerciantes ambulantes que existen en el Centro Histórico, así como las organizaciones que lo componen. Según la Dirección de Comercio, el número de puestos se duplicó en las pasadas dos administraciones (2009 a 2015, respectivamente), ya que en 2007 apenas rebasaba los mil puestos. La información contenida en dicha tabla, señala la existencia de 3175 puestos ambulantes dentro de la ciudad de San Luis Potosí, específicamente en la zona centro. Del total, 1050 locatarios ambulantes se ubican dentro del perímetro A del Centro Histórico.

Desde los años ochenta en adelante, diversas administraciones estatales y municipales han intentado acotar espacialmente la ubicación del comercio ambulante. Existen cuatro espacios construidos ex profeso en diferentes años, tales como los mercados "La Pulga", Allende, San Luis 400 y Tomás Vargas. En 2017, se planea construir un quinto mercado denominado Tepeché, que se localizará también en la zona centro, cuyo "éxito" se

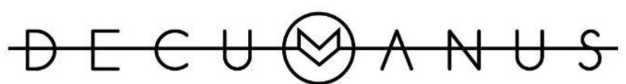

REVISTA INTERDISCIPLINARIA SOBRE ESTUDIOS URBANOS 
Tabla 1. Organizaciones de comerciantes ambulantes dentro del Centro Histórico.

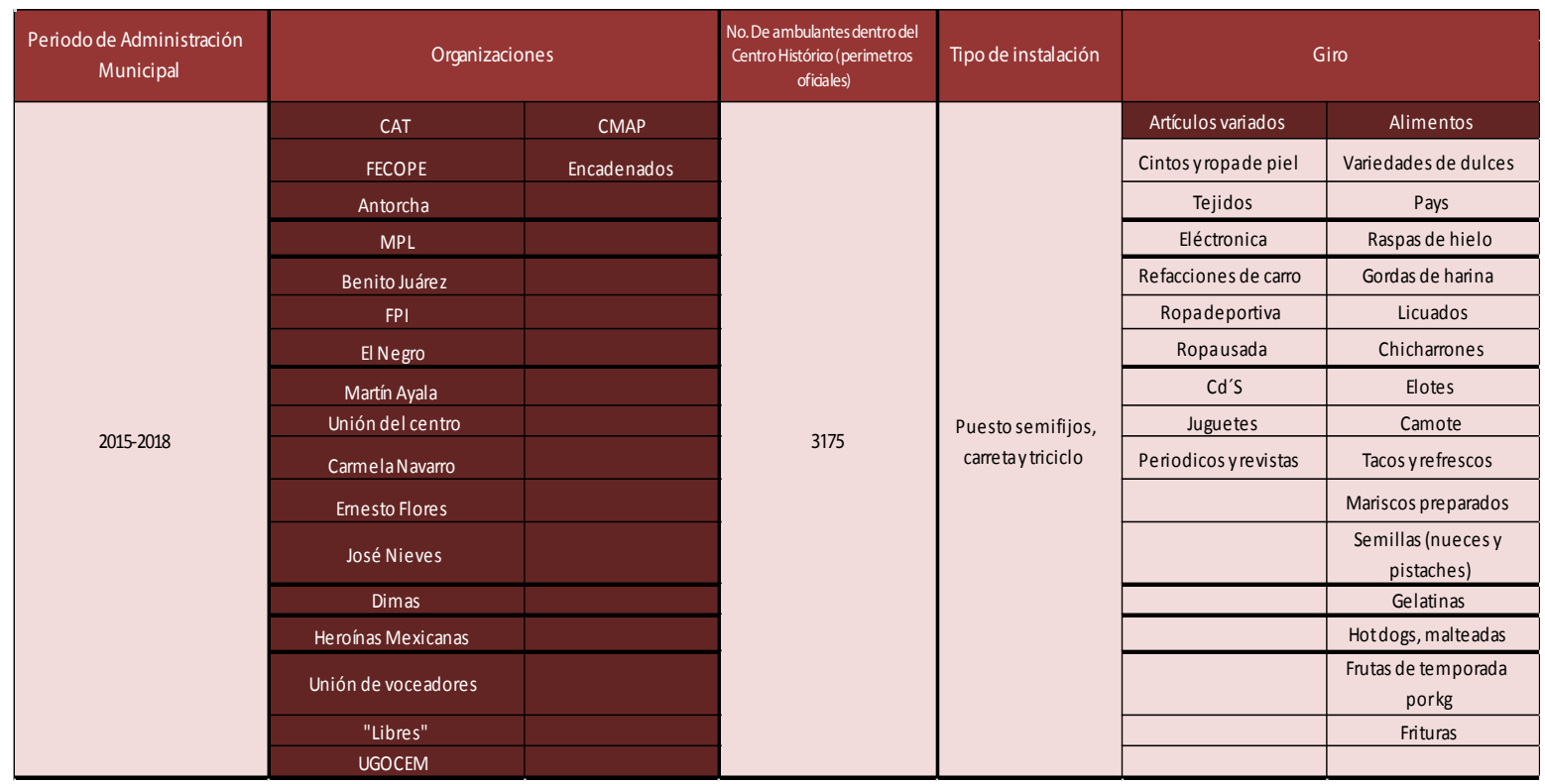

Fuente: elaboración propia con base en los censos de puestos ambulantes dentro del perímetro oficial del Centro Histórico de San Luis Potosí; Dirección de Comercio del H. Ayuntamiento de

San Luis Potosí (enero de 2017).

pondera de manera anticipada por las autoridades municipales, ya que se encuentra cerca de uno de los mercados formales más importantes: el República. Después de muchos años de tolerar este fenómeno, durante la administración municipal de Ricardo Gallardo Juárez (2015-2018), se ha tratado de enfrentar este problema por medio del desalojo y la fuerza pública hacia los comerciantes ambulantes del Centro Histórico. No obstante, las acciones de protesta y resistencia por parte de las asociaciones a las que pertenecen los ambulantes, no se han hecho esperar. Así, en 2016 se realizaron marchas y cierre de calles rehusándose a abandonar el espacio público, lo que ocasionó a lo largo del año situaciones de caos vial y social en el Centro Histórico.
Accesibilidad y movilidad al Centro Histórico y su conexión con el comercio ambulante

La ciudad de San Luis Potosí se funda en 1592, durante la época de la Colonia. Durante los primeros trescientos años creció, a partir de su núcleo histórico y de los barrios iniciales, hacia la periferia de forma progresiva con un modelo clásico de las ciudades novohispanas, prácticamente inalterado en todo ese tiempo y en el que el centro antiguo estableció los límites espaciales de la ciudad. A partir del siglo xx, este modelo comenzó a modificarse lentamente y a mediados de dicho siglo adopta un patrón de crecimiento de tipo concéntrico, combinado con otro de corte radial sectorial. Desde entonces, y en particular en las últimas dos décadas (1990-2010), este crecimiento se ha vuelto expan-

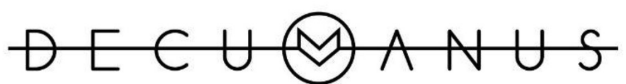

REVISTA INTERDISCIPLINARIA SOBRE ESTUDIOS URBANOS 
sivo, fragmentado e insustentable. El modelo de crecimiento expansivo, se caracteriza por bajas densidades demográficas, ocupación de suelo residencial en detrimento de áreas naturales protegidas y de cobertura vegetal, movilidad insustentable y uso desmedido del automóvil privado como principal medio de transporte (Moreno, 2015; López, 2017).

La figura 3 ilustra con claridad la fragmentación y desorden que caracterizan al sistema de movilidad y transporte en toda la zona metropolitana, pero en particular en el Centro Histórico de la ciudad. Uno de los rasgos característicos, es que prácticamente todas las rutas de transporte público llegan o salen del área central. Debido a la forma en la que están distribuidas las rutas, los usuarios de este servicio deben hacer transbordos hacia otras rutas, que les permitan desplazarse a otros puntos de la ciudad. En global, se identifican veintiún rutas de transporte que llegan o salen del Centro Histórico y su flujo se concentra en los puntos de ascenso y descenso de pasajeros, cuyos desplazamientos son por motivos laborales, educativos, de consumo, de recreación o de ocio (López, 2017) (véase figura 4).

El caso específico del corredor urbano Eje Via, es prototípico de esta problemática: la concentración de rutas de transporte público, el número de unidades vehiculares que pasan por el corredor, el número de paradas de autobús y la afluencia creciente de peatones, al combinarse con una red vial mal planeada, insuficiencia de estacionamientos y presencia del comercio ambulante, generan una situación caótica en términos de movilidad y transporte, en particular durante las horas pico (véase figura 5).

Existen varios motivos para que los vendedores ambulantes, se ubiquen a lo largo de este corredor: i) Principal: una gran afluencia cotidiana de peatones que se convierten en compradores potenciales; ii) Muchos vendedores habitan en las vecindades de la proximidad y las céntricas casonas deterioradas son los almacenes ideales para guardar sus puestos y mercancías al terminar cada día. Hay que hacer notar que los ambulantes, se ubican en calles que tienen mayor circulación para vender mejor (y no en calles vacías), agravando, con ello, el problema de movilidad interna dentro del Centro Histórico.

Percepción del Centro Histórico de San Luis Potosí en relación con el ambulantaje

Derivado de las entrevistas realizadas, se obtuvieron los siguientes resultados, de acuerdo con el tipo de actor clave entrevistado (véase tabla 2):

a) Ciudadano en general: quienes frecuentan el Centro Histórico, en 90 $\%$ de los casos opinan que el comercio ambulante se genera por falta de oportunidades en el sector de empleos y por los salarios bajos que existen en la ciudad. A su vez, $100 \%$ de los entrevistados consideran que la existencia de estos puestos ambulantes genera una pobre imagen urbana, poco atractiva y sucia del Centro Histórico, en general, pero en especial repulsiva para los visitantes o turistas. Existe una opinión generalizada (100 \%)

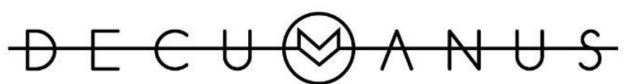

REVISTA INTERDISCIPLINARIA SOBRE ESTUDIOS URBANOS
Núm. 2. Vol. 2. Octubre 2016-Octubre 2017. Instituto de Arquitectura, Diseño y Arte.

Universidad Autónoma de Ciudad Juárez. ISSN: 2448-900X 
Figuras 3 y 4. Zona metropolitana de San Luis Potosí. Rutas de transporte público y flujos vehiculares.
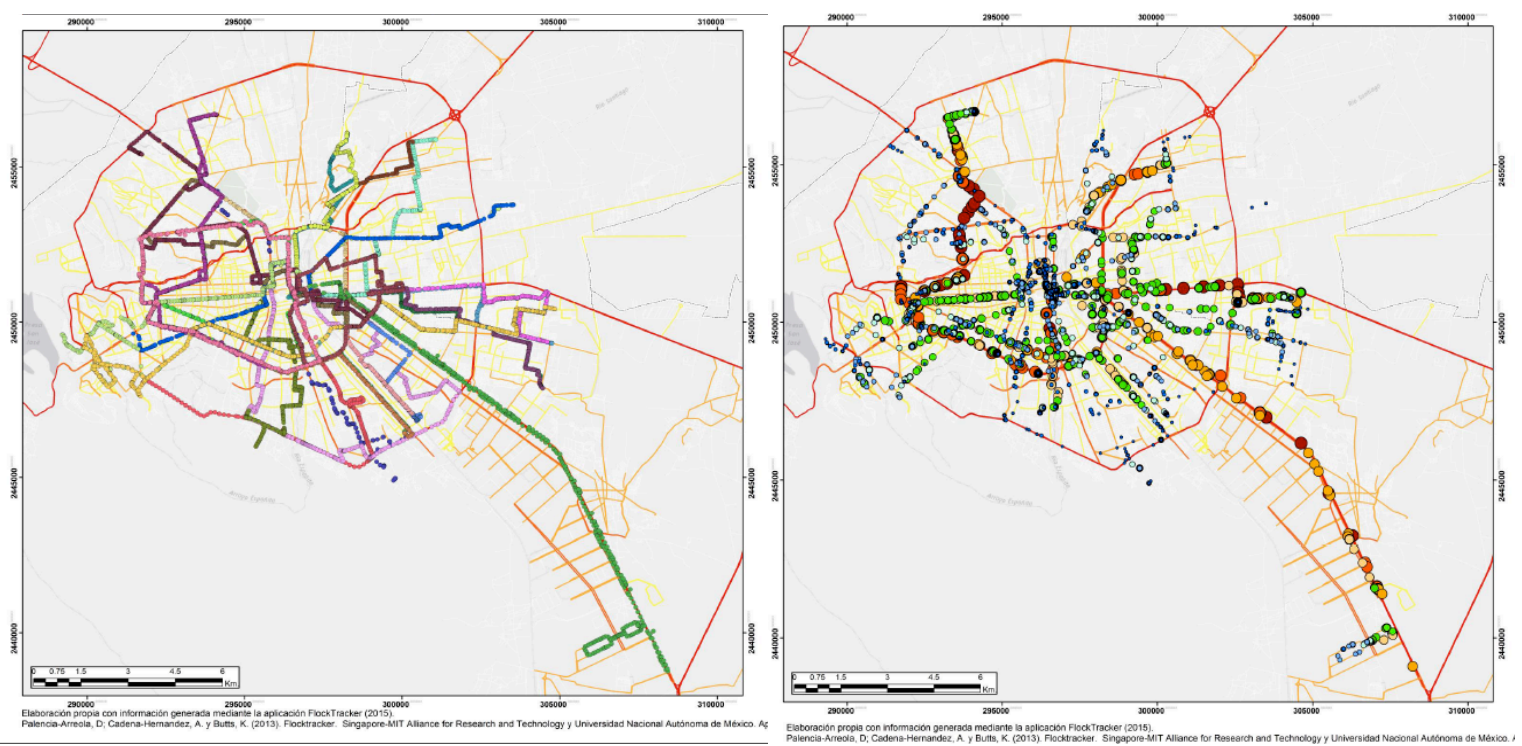

Fuente: López (2017).

Figura 5. Área de estudio (corredor urbano Eje Vial; paradas de autobús).

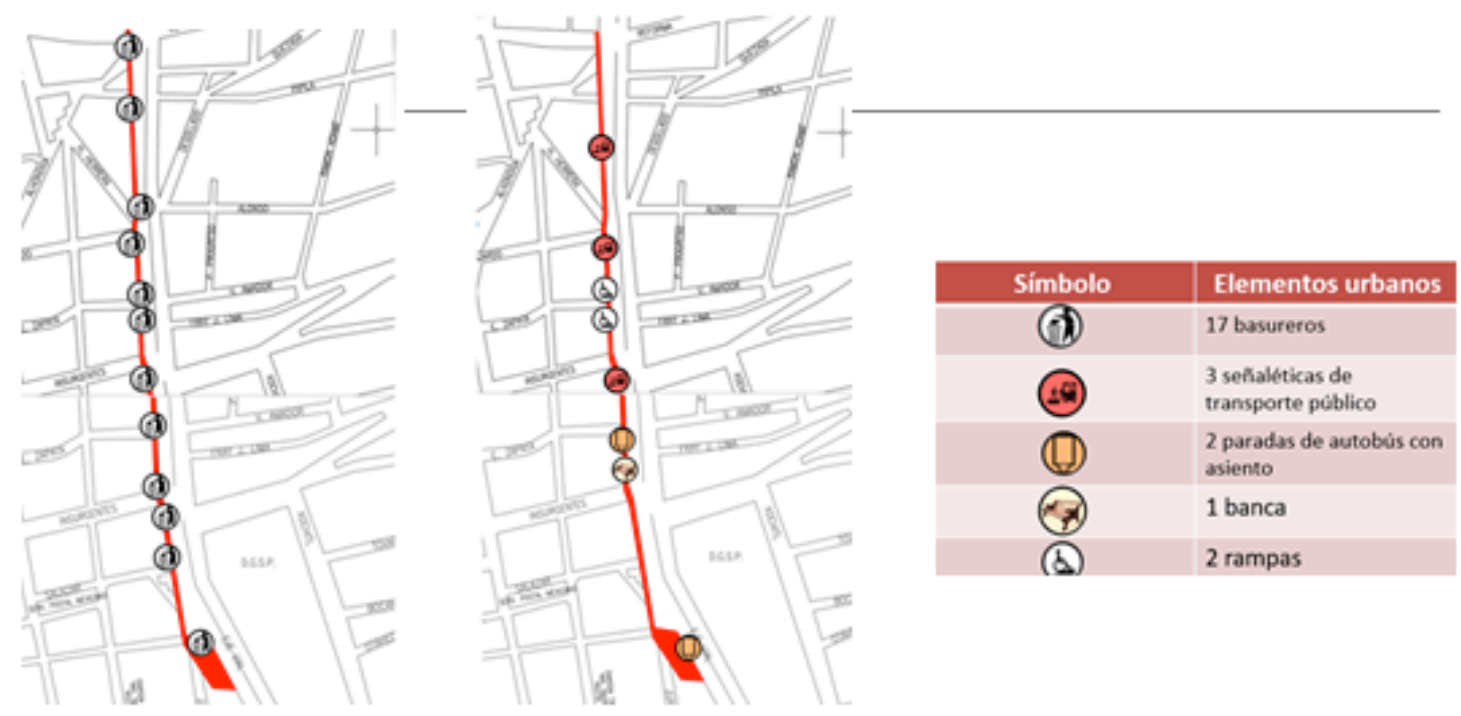

Fuente: Beltrán (2017).

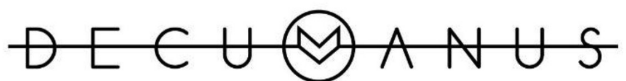

REVISTA INTERDISCIPLINARIA SOBRE ESTUDIOS URBANOS 
que percibe al mobiliario urbano en completo estado de abandono y con una baja legibilidad en las nomenclaturas y señalizaciones (por ejemplo, en el transporte urbano), además de la molestia o riesgos que genera la instalación de toldos "provisionales" mediante cuerdas que los sostienen y que cruzan las vialidades, dificultando la movilidad peatonal e impidiendo la accesibilidad a ciertos espacios públicos. La mayor parte de los entrevistados muestran un descontento con la existencia de puestos de comerciantes ambulantes, pero aceptan que suelen comprar productos en ellos (en su mayoría alimentos) por sus precios bajos y cercanía a las paradas del transporte público.

b) Comerciantes ambulantes: el 100 $\%$ de comerciantes ambulantes entrevistados opinaron que su puesto semifijo no genera problemas a los peatones o a la visibilidad del lugar y que, para ellos, su trabajo en las calles es respetable como el de cualquier comerciante o locatario formal. Solo $40 \%$ de los entrevistados perciben algún grado de inseguridad en su entorno de trabajo, mientras que el resto no muestran temor a lo que podría suceder, revelando, por el contrario, una gran seguridad basada en la solidaridad de sus organizaciones y en el apoyo político y legal que estas les prestan, lo que implica una gran fuerza social por parte de estos grupos y una posición monolítica que se rige, en gran medida, por la opinión de sus líderes. No obstante, un porcentaje ele- vado (70 \%) de comerciantes ambulantes entrevistados creen que las autoridades los retirarán sin previo aviso. En términos de cualidades espaciales, $60 \%$ consideran tener el espacio adecuado para ejecutar su actividad económica. Además, comentaron que su ideal para sentirse satisfechos al ser removidos, sería un lugar como una plaza comercial y no un mercado ubicado en sitios de poca accesibilidad, como comúnmente sucede.

c) Servidores públicos: existe una opinión generalizada (100 \% de servidores públicos entrevistados) de que los comerciantes ambulantes que se encuentran dentro del primer cuadro del Centro Histórico cuentan con permisos para instalarse, mientras que $80 \%$ de los entrevistados opinan que los únicos problemas que se generan son cuando no acatan órdenes (como quitar la estructura semifija de sus puestos por las noches o apropiarse de más espacio que el asignado). Respecto al factor percepción, $100 \%$ de los funcionarios entrevistados manifestaron que la localización del comercio ambulante en el Centro Histórico se encuentra estrechamente asociada con altos indices de delincuencia (robos, asaltos a mano armada, etcétera). En relación con las cualidades espaciales, $90 \%$ de los entrevistados opinan que la presencia del comercio ambulante en el centro de la ciudad, es un factor importante tanto en el deterioro de la imagen urbana como en el empobrecimiento del aspecto fisico y socioeconómico de la zona

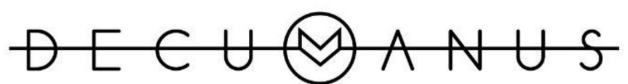

REVISTA INTERDISCIPLINARIA SOBRE ESTUDIOS URBANOS
Núm. 2. Vol. 2. Octubre 2016-Octubre 2017. Instituto de Arquitectura, Diseño y Arte.

Universidad Autónoma de Ciudad Juárez. ISSN: 2448-900X 
Tabla 2. Resultados de las entrevistas a actores clave por tipo y factor.

\begin{tabular}{|c|c|c|c|c|c|c|}
\hline $\begin{array}{l}\text { Categorias ana- } \\
\text { líticas }\end{array}$ & $\begin{array}{l}\text { Ciudadano } \\
\text { en general }\end{array}$ & $\%$ & $\begin{array}{l}\text { Comerciante } \\
\text { ambulante }\end{array}$ & $\%$ & $\begin{array}{c}\text { Servidor } \\
\text { público }\end{array}$ & $\%$ \\
\hline \multirow[t]{4}{*}{ Accesibilidad } & $\begin{array}{c}\text { Origen del problema: } \\
\text { se ubica en la esfera } \\
\text { económica }\end{array}$ & 90 & \multirow{4}{*}{$\begin{array}{l}\text { Comerciantes am- } \\
\text { bulantes no son } \\
\text { problema con la } \\
\text { accesibilidad y } \\
\text { cruce del lugar }\end{array}$} & \multirow{4}{*}{100} & \multirow[t]{2}{*}{$\begin{array}{l}\text { Comerciantes ambulan- } \\
\text { tes cuentan con permi- } \\
\text { sos para instalarse }\end{array}$} & \multirow[t]{2}{*}{100} \\
\hline & \multirow{2}{*}{$\begin{array}{l}\text { Entorpecimiento del } \\
\text { flujo peatonal }\end{array}$} & \multirow[t]{2}{*}{100} & & & & \\
\hline & & & & & \multirow[b]{2}{*}{$\begin{array}{l}\text { Impacto espacial del } \\
\text { comercio ambulante: se } \\
\text { reduce a la apropiación } \\
\text { de más espacio que del } \\
\text { asignado }\end{array}$} & \multirow[b]{2}{*}{80} \\
\hline & $\begin{array}{l}\text { Aglomeración de per- } \\
\text { sonas genera estrés y } \\
\text { enojo entre los pea- } \\
\text { tones }\end{array}$ & 95 & & & & \\
\hline \multirow[t]{3}{*}{$\begin{array}{l}\text { Percepción del } \\
\text { usuario }\end{array}$} & $\begin{array}{l}\text { Lugar inseguro con } \\
\text { alta probabilidad de } \\
\text { ser asaltados }\end{array}$ & 100 & $\begin{array}{l}\text { Perciben el lugar } \\
\text { con inseguridad en } \\
\text { el entorno laboral }\end{array}$ & 40 & \multirow[t]{3}{*}{$\begin{array}{l}\text { Ambiente de insegu- } \\
\text { ridad generado por la } \\
\text { delincuencia }\end{array}$} & \multirow{3}{*}{10} \\
\hline & $\begin{array}{l}\text { Ruido constante por } \\
\text { venta de música y } \\
\text { películas piratas }\end{array}$ & 100 & \multirow{2}{*}{$\begin{array}{l}\text { Perciben que po- } \\
\text { drían ser desaloja- } \\
\text { dos por las auto- } \\
\text { ridades sin ningún } \\
\text { aviso }\end{array}$} & \multirow[t]{2}{*}{60} & & \\
\hline & $\begin{array}{l}\text { Malos olores prove- } \\
\text { nientes de las cañerías }\end{array}$ & 90 & & & & \\
\hline \multirow[t]{2}{*}{$\begin{array}{l}\text { Cualidades } \\
\text { espaciales }\end{array}$} & \multirow[t]{2}{*}{$\begin{array}{l}\text { Se perciben elementos } \\
\text { físicos con dificultad } \\
\text { por la intervención de } \\
\text { puestos en banquetas }\end{array}$} & \multirow[t]{2}{*}{90} & $\begin{array}{c}\text { Creen tener el } \\
\text { espacio necesario } \\
\text { para desempeñar } \\
\text { su actividad eco- } \\
\text { nómica }\end{array}$ & 60 & \multirow[t]{2}{*}{$\begin{array}{l}\text { Imagen urbana deterio- } \\
\text { rada e idea de un lugar } \\
\text { empobrecido por su } \\
\text { aspecto fisico y socioe- } \\
\text { conómico }\end{array}$} & \multirow[t]{2}{*}{90} \\
\hline & & & $\begin{array}{l}\text { Observan el lugar } \\
\text { descuidado: por } \\
\text { ejemplo, edificios y } \\
\text { banquetas }\end{array}$ & 30 & & \\
\hline
\end{tabular}

Fuente: Beltrán (2017) con base en trabajo de campo.

de estudio. También se afirmó que no existe un control del uso o robo de energía eléctrica que cotidianamente utilizan los comerciantes ambulantes, al "colgarse" de cables de alta tensión por medio de diablitos, lo cual puede tener consecuencias peligrosas para el resto de la población. De igual manera, los entrevistados argumentaron que se tiene previsto una ubicación específica para el reacomodo del comercio ambulante existente en el Centro Histórico en un mercado específico, pero que por el momento se encuentran en pláti- cas de convencimiento con líderes de organizaciones de comerciantes ambulantes.

\section{Cualidades espaciales, según percep- ción e identificación de problemas}

Las cualidades o deficiencias espaciales que se observaron en el área de estudio, la identifican como un lugar peligroso para el tránsito cotidiano, no solo por la presencia de asaltantes, carteristas y otro tipo de delincuentes, sino también por su coexistencia con la prostitución-lenocinio y otros "giros negros", como hoteles de paso, bares y

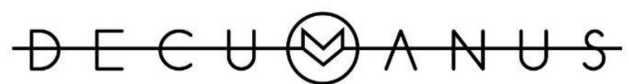

REVISTA INTERDISCIPLINARIA SOBRE ESTUDIOS URBANOS
Núm. 2. Vol. 2. Octubre 2016-Octubre 2017. Instituto de Arquitectura, Diseño y Arte.

Universidad Autónoma de Ciudad Juárez. ISSN: 2448-900X 
cantinas, y la localización de diversas vecindades con población de escasos recursos y en condiciones precarias, que muchas veces se utilizan parcial o totalmente para la práctica de la prostitución. Estas actividades generan un ambiente hostil para el usuario o transeúnte y promueven una imagen urbana deteriorada. En las figuras 6, 7 y 8 , se aprecia la distribución espacial de esas actividades a lo largo del corredor urbano Eje Vial, en el tramo analizado, cuyo mapeo fue posible a partir de las entrevistas realizadas y el trabajo de campo, destacándose tres rubros importantes: i) Robos y asaltos; ii) Prostitución; y iii) Tráfico vial.

1. Robos y asaltos: se generan principalmente en las paradas del transporte público, así como en la entrada de calles y callejones, y en los accesos a las vecindades, donde la luz de las luminarias se ve limitada por la presencia de frondosos árboles y la mala calidad del alumbrado público. Esta situación se extiende a lo largo del tramo vial analizado y afecta, principalmente, a estudiantes y personas jóvenes. Por la noche, se convierte en un conflicto mayor en donde se entremezclan, principalmente, la prostitución y asaltos con violencia a mayor escala (balaceras, peleas entre cárteles, etcétera).

2. Prostitución: se lleva a cabo, principalmente, en la calle Del Codo (un pasillo peatonal que termina en la calle de Salazar, la cual desemboca en la avenida de Eje Vial, Salazar, Tovar y Escontría, donde se ubican las vecindades en las que se presta este servicio entremezcladas con viviendas antiguas unifamiliares). Las personas que se dedican a dicha actividad, se localizan de manera predominante a lo largo del corredor vial, en las esquinas y regularmente se encuentran entre las diez de la mañana y altas horas de la madrugada. El problema de la prostitución genera un ambiente de alto conflicto social, mayor inseguridad y una imagen urbana poco favorable para el área de estudio. Asimismo, la obsolescencia típica del parque edilicio y la presencia del comercio ambulante en establecimientos en mal estado, contribuyen a la pérdida de valor del Centro Histórico.

3. Tráfico vial: el que se genera en el área de estudio, es caótico, con una gran intensidad y afluencia en horas pico, serios problemas de tránsito vial y accidentes continuos. La presencia de paradas del transporte público a lo largo del tramo estudiado, promueve un mayor conflicto entre transeúntes, usuarios del transporte, vehículos y vendedores ambulantes. Uno de los principales problemas que se genera por la conflictiva relación entre tráfico vial, transporte público y comercio ambulante, se deriva de las dificultades del tránsito peatonal que producen los puestos ambulantes, muchos de los cuales abarcan todo el ancho de las banquetas e, incluso, invaden la vialidad, entorpeciendo el flujo normal de peatones y vehículos, además del cruce de las calles, y provocando accidentes viales.

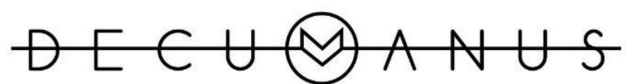

REVISTA INTERDISCIPLINARIA SOBRE ESTUDIOS URBANOS
Núm. 2. Vol. 2. Octubre 2016-Octubre 2017. Instituto de Arquitectura, Diseño y Arte.

Universidad Autónoma de Ciudad Juárez. ISSN: 2448-900X 
Figuras 6-8. Área de estudio (corredor urbano Eje Vial; conflictos urbanos).
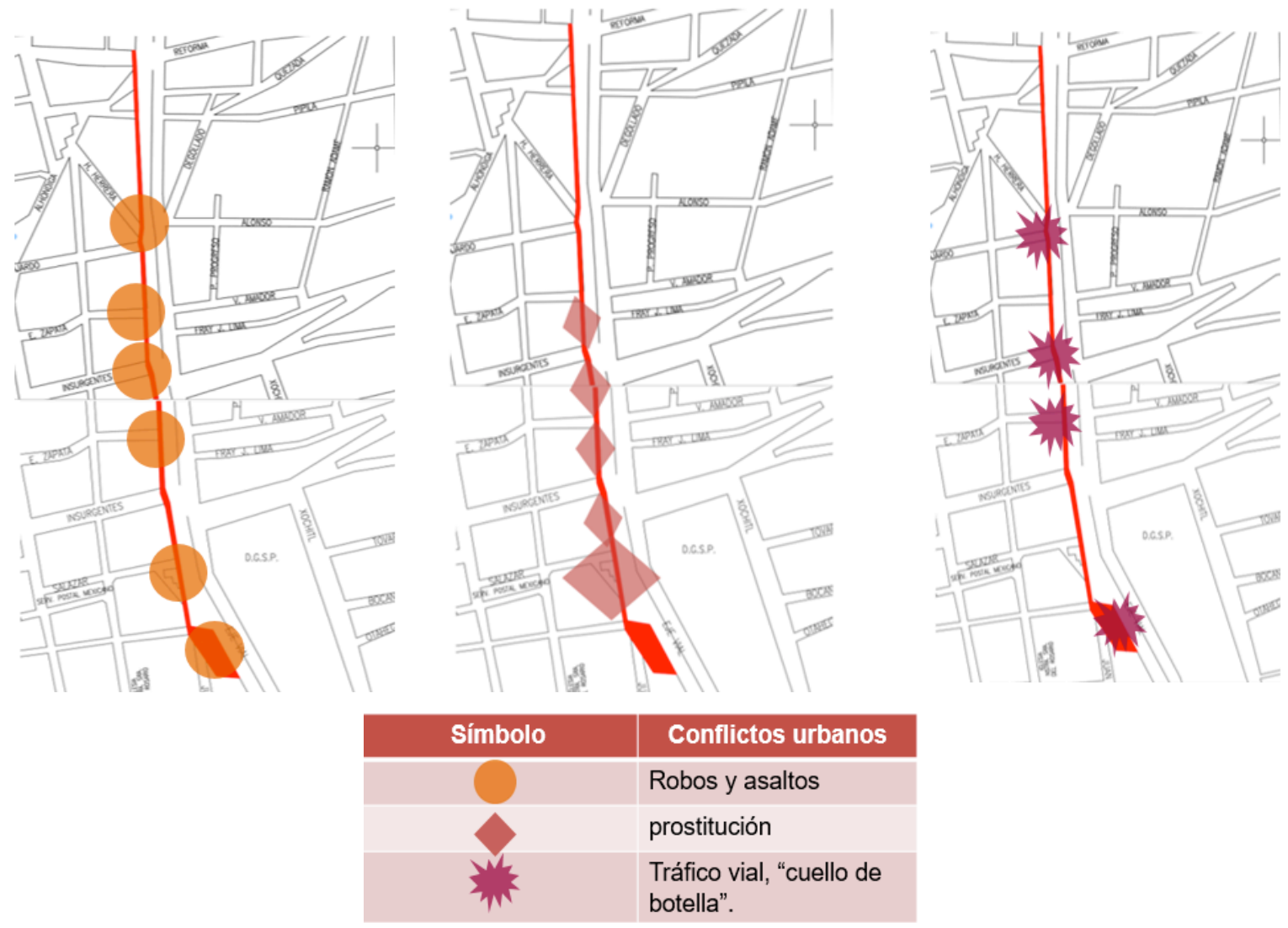

Fuente: Beltrán (2017).

\section{Conclusiones y recomendaciones}

De acuerdo con los resultados de la investigación, es posible concluir que la dinámica del comercio ambulante (que incluye intereses económicos y políticos) y la permisiva postura de las autoridades, constituyen los factores explicativos del fenómeno del ambulantaje y de la distribución espacial de este tipo de comercio. Se plantea que una política pública exitosa que enfrente este problema, debería considerar esos componentes, así como un cambio sustancial en la manera de abordarlos.
Respecto a la imagen urbana de los espacios públicos en el Centro Histórico de la ciudad de San Luis Potosí, los resultados de la encuesta aplicada revelan que es un aspecto muy importante para el ciudadano común. Dependiendo de la percepción que se tiene del lugar, los usuarios han construido una imagen mental en donde lo encuentran confiable o no, accesible o no. Basado en las experiencias individuales o colectivas (compartidas), la imagen percibida del espacio público en el caso de estudio parece connotar más aspectos negativos que positivos. Lo mismo sucede con la opinión del turismo cultural, debido principalmente al caos urbano que genera esa

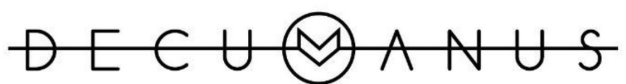

REVISTA INTERDISCIPLINARIA SOBRE ESTUDIOS URBANOS 
actividad. La información cualitativa deja entrever experiencias e imágenes mentales de carácter negativo por parte del habitante común y los usuarios del espacio público en ese sector de la ciudad, aunado al poco deseo de permanecer en ese lugar. Se aprecia también una percepción, más o menos generalizada, de inaccesibilidad o accesibilidad limitada para todos, derivada de la localización indiscriminada del comercio ambulante, que atenta contra el Derecho a la Ciudad.

Sin embargo, la expansión del área de influencia del comercio ambulante en el Centro Histórico de la ciudad de San Luis Potosí, acentuada en las últimas dos décadas, podría comprenderse como un fenómeno con distintas facetas:

- Por un lado, la existencia y distribución espacial del comercio ambulante en el Centro Histórico de la ciudad de San Luis Potosí, sería un reflejo de las tendencias de la economía local y nacional $-\mathrm{y}$ aún global-, de las alternativas u oportunidades de las personas para generar un autoempleo y subsistir. Ello implica afiliarse a grandes organizaciones de comerciantes informales y entrar a la esfera de control de líderes poderosos, pero también establecerse y "sobrevivir" en las calles, con las consecuencias que puede ocasionar hacerlo en un lugar "temporal" (de acuerdo con el orden urbano) de manera indefinida.

- Por el otro, podría observarse como un proceso de apropiación del espacio público por parte de comerciantes ambulantes en el que intervienen tanto intereses privados como públicos, en los que prevalece la visión de una ciudad capturada por un movimiento de "resistencia" y "reapropiación" de ese espacio.

- Una tercera vertiente explicativa del problema, desde la perspectiva urbana, es que en su dinámica y evolución se traslapan, siguiendo a Mongin (2017), los distintos flujos que configuran a la ciudad: i) Flujos económicos: determinados por la localización de actividades y servicios que pueden ofrecer los centros históricos, incluidos primordialmente los de orden turístico; ii) flujos espaciales: influidos por la reglamentación, usos del suelo y, en general, el marco normativo urbano, que impone un zonning urbano y modalidades específicas de movilidad; y iii) flujos ideales: podrían hacer compatibles los distintos intereses, redes y flujos que se integran en el espacio público del Centro Histórico y hacer de este un espacio más funcional, integrado en términos espaciales, así como un lugar de convivencia social.

¿Qué puede hacerse para enfrentar esta situación desde el ámbito de la política urbana?

Un primer punto se refiere a poner en cuestión los resultados obtenidos en los últimos veinte años (2008-2017) por las diversas acciones públicas emprendidas en el Centro Histórico de la ciudad de San Luis Potosí, tanto por los distintos órdenes de gobierno (federal, a través del Instituto Nacional de Antropología e Historia (INAH),

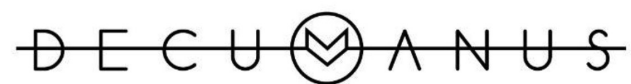

REVISTA INTERDISCIPLINARIA SOBRE ESTUDIOS URBANOS 
Consejo Nacional para la Cultura y las Artes (Conaculta), etcétera; estatal, a través de la Secretaría de Desarrollo Urbano, Vivienda y Obras Públicas, Secretaría de Desarrollo Económico, y municipal) como por la sociedad (Consejo Consultivo del Centro Histórico, cámaras de comercio, etcétera). Ello incluye la inversión canalizada para apoyar diversos estudios (Proyecto de Regeneración del Centro Histórico, Expediente Traza Procesional; Plan Parcial del Centro Histórico) - por cierto, muy costosos-, cuyos objetivos eran transformar de fondo las condiciones materiales, económicas, sociales y ambientales en las que se debate el Centro Histórico; aprovechar su riqueza patrimonial; impulsar proyectos de conservación y (re)generación; reactivar la dinámica económica local y estimular usos y reglas que incidan en la forma de vivir, prácticas sociales y modalidades de apropiación del espacio público (HSLP, 2007).

A pesar de la visión triunfalista y de optimismo desbordado por los sectores gobierno y privado, los resultados obtenidos son muy dudosos: la mayoría de los proyectos y acciones, se han quedado en el tintero y los que se han llevado a la práctica responden más bien a un enfoque de políticas neoliberales basado en acciones con fines económicos, pero ajenas a la opinión y percepción de usuarios y pobladores. Un enfoque que se apoya en la idea de ciudad-museo y en la de obras de ingeniería pseudoarquitectónicas, donde al Centro Histórico se le considera como un escenario, un montaje que intenta ser agradable a la vista de turistas y con el paisaje urbano-artificial del área central y de sus barrios, y fomentar actividades suntuarias y de ocio para consumidores de altos ingresos.

Quedan a deber dichos estudios y acciones un análisis más profundo de las prácticas cotidianas sociales que se desarrollan en el Centro Histórico de la ciudad de San Luis Potosí y, en particular, de sus espacios públicos aspecto que, por cierto, sí abordan investigaciones elaboradas en el ámbito académico y pasar de una simple idea de proteger o preservar el patrimonio cultural a la de proponer el uso y convivencia social del espacio público.

Al respecto, no es necesario quebrarse la cabeza. Existen numerosos ejemplos exitosos de políticas de conservación y rehabilitación urbanas de los centros históricos desarrollados en distintos niveles (local, nacional, regional), que promueven la protección integral de las áreas centrales antiguas, abordando, al mismo tiempo, problemas culturales, arquitectónicos, funcionales, ambientales, económicos y sociales que la ciudad contemporánea evidencia, y llegando a su solución equilibrada (Unesco, 2010). Además, la intervención en los centros históricos requiere de un esfuerzo colectivo y transdisciplinario, que desde un enfoque sistémico de los problemas pueda identificar estrategias para la conservación y reutilización urbanas capaces de integrar los múltiples aspectos espaciales, formales, culturales y socioeconómicos que connotan su existencia y la de la población que trabaja y vive en los centros históricos.

Las políticas para los centros históricos deben aspirar a la continuidad en el tiempo, es decir, a la sustenta-

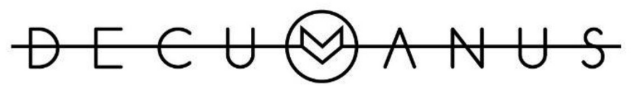

REVISTA INTERDISCIPLINARIA SOBRE ESTUDIOS URBANOS
Núm. 2. Vol. 2. Octubre 2016-Octubre 2017. Instituto de Arquitectura, Diseño y Arte.

Universidad Autónoma de Ciudad Juárez. ISSN: 2448-900X 
bilidad. Más allá de la sucesión de las estructuras gubernamentales de las distintas inspiraciones politicas, las acciones de gobierno deben guiarse por principios de gobernabilidad en términos de sostenibilidad cultural, medioambiental, económica y social. La gobernabilidad garantiza la consolidación del rol del sector público, a través del establecimiento de regulaciones y procedimientos, y el carácter multiactoral y multiescalar que ha de tener todo proceso holístico de rehabilitación urbana, haciendo posible, además, la sostenibilidad de otras dimensiones estratégicas del desarrollo:

- La sostenibilidad cultural asegura la recuperación, permanencia y generación de valores culturales, tanto materiales como espirituales; el fortalecimiento de patrones identitarios de la ciudad y de la sociedad que en ella vive; y la salvaguarda del paisaje urbano. La sostenibilidad medioambiental promueve un uso racional de recursos y atiende problemas directamente relacionados con el bienestar de los individuos, su seguridad y la preservación del contexto urbano y medioambiental.

- La sostenibilidad económica promueve la consolidación e innovación de las economías locales que hacen posible la materialización de planes y programas dinámicos y competitivos.

- La sostenibilidad social tiende a responder a la efectiva demanda social y a resolver graves conflictos sociales - por ejemplo, inseguridad, delincuencia, prostitución-, que involucran a la ciudadanía y cuya solución debe incorporar un enfoque de equidad y de género.

- La sostenibilidad ambiental permite revertir los graves procesos de contaminación atmosférica, acústica, de insalubridad y visual, que afectan a los centros históricos.

En esta serie de recomendaciones no puede obviarse la fuerte tendencia a la terciarización de los centros históricos y su transformación en zona comercial o residencial elitista o su abandono para usos exclusivamente turísticos, que inevitablemente producen la pérdida de su significación urbana o pauperización. La recalificación o "puesta en valor" de los centros históricos, debe salvaguardar su uso residencial desde un programa de equidad social y de equilibrio entre las funciones que en él se encuentran o se pueden desarrollar. Se tiene que regular la organización del territorio urbano de forma clara y precisa, para dar respuestas adecuadas al mayor número de actores que forman parte de un proceso basado en la conservación de valores del pasado, el uso adecuado del patrimonio cultural común, la preservación de sus significados e identidad, y la capacidad de añadir nuevos valores y simbolismos.

La mejora del espacio público juega un rol estratégico para la rehabilitación de los centros históricos. La atención a la calidad del espacio público fortalece la importancia de la ciudad como un lugar de vida y de relaciones sociales, y fomenta la participación de la inversión privada en la recuperación del patrimonio histórico. El espacio público es el escenario más directo de los conflictos y de las tensiones so-

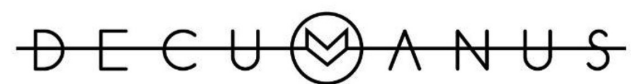

REVISTA INTERDISCIPLINARIA SOBRE ESTUDIOS URBANOS 
ciales y económicas que, día tras día, la ciudad enfrenta. La degradación urbana, la expresión de la marginalidad o caos en los espacios públicos y la falta de orden, generan percepción de peligrosidad, a veces real, a veces mitificada, que provoca externalidades negativas, haciendo del sitio un lugar poco atractivo para los habitantes, los visitantes, los inversores.

Otro factor fundamental de degradación del espacio público, se determina por la reglamentación carente de una visión de la movilidad urbana, el tráfico y la dificultad de uso peatonal en las calles a causa de la fuerte presencia de automóviles. Una planeación más racional de los espacios públicos, puede redimirlos de la degradación y del anonimato, a través de la creación de condiciones para incentivar la recuperación generalizada del patrimonio por parte del sector privado.

El derecho colectivo al Centro Histórico significa que su conservación es un problema de interés general. En este sentido, para la rehabilitación efectiva de los centros históricos se tiene que activar un flujo continuo y confiable de recursos, que permitan la programación de intervenciones que se quieren lograr a corto y mediano plazos. No dejarlas inconclusas o modificar sus alcances por limitaciones financieras o una mala programación presupuestal o, peor aún, una desviación de los recursos públicos y privados. Hay que diversificar las fuentes de financiamiento, atendiendo la participación de inversiones privadas, de mecanismos de asociación público-privada y de experiencias cooperativas para viviendas y servicios. El sector público tiene que incentivar, apoyar y regular las acciones de particulares, para que el sector privado invierta más recursos en recuperar no solo los edificios, sino especialmente los sectores urbanos degradados y vulnerables. Un buen ejemplo sería imponer el sistema de recuperación de plusvalías.

\section{Bibliografia}

Arditi, B. (Ed.) (2005). ¿Democracia post-liberal? El espacio político de las asociaciones. Revista Mexicana de Sociología, 68(4).

Arendt, H. (1958). La condición humana. Chicago: University of Chicago Press.

Augusto, F. R., \& Flórez Millán, L. Á. (2005). Estado del arte del concepto. Diseño urbano. Revista de Arquitectura, 7, 3941.

Baudrillard, J. (1980). El espejo de la producción (Le miroir de la production, Casterman, 1973, trad. Irene Agoff). Barcelona: Gedisa.

Bauman, Z. (2001). La sociedad individualizada. Cambridge, Massachusetts: Polity Press.

Beltrán Moncada, C. (2017). Apropiación del espacio público por medio de la informalidad urbana en la zona metropolitana de San Luis Potosí. Tesis de Maestría en Ciencias del Hábitat. México: Instituto de Investigación y Posgrado, Facultad del Hábitat, UASLP.

Borja, J. (2003). La ciudad conquistada. Madrid: Alianza.

Borja, J., \& Muxí, Z. (2000). El espacio público, ciudad y ciudadanía. Barcelona: Editorial Alianza.

Carrión, F. (2007). Financiamiento de los centros históricos de América Latina y

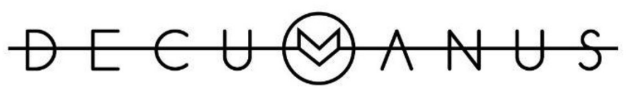

REVISTA INTERDISCIPLINARIA SOBRE ESTUDIOS URBANOS
Núm. 2. Vol. 2. Octubre 2016-Octubre 2017. Instituto de Arquitectura, Diseño y Arte.

Universidad Autónoma de Ciudad Juárez. ISSN: 2448-900X 
el Caribe. Quito: Flacso - Sede Ecuador - Lincoln Institute of Land Policy.

Castillo, J. (1996). Psicología ambiental, naturaleza y cultura. Santiago: Ediciones Por la Vida.

Castillo, M. (2003). Vía pública y comercio informal en la Ciudad de México. México: Limusa.

Coulomb, R. (2010). México: centralidades históricas y proyectos de ciudad. Quito: Olacchi.

De Certeau, M. (1996). La invención de lo cotidiano. México: Universidad Iberoamericana.

Fuentes Gómez, J. H., \& Formoso Sierra, Z. (2008). Representaciones y discursos sobre multiculturalidad, identidad y patrimonio urbanos del Programa Mérida, Capital Americana de la Cultura, 2000. Cuicuilco, 15(42).

Galeano Rojas, S. M., \& Beltrán Camacho, R. B. (2008). Ciudad, informalidad y políticas públicas: una reflexión desde la sociología de lo cotidiano. Cuadernos de Vivienda y Urbanismo, 1(2): 280-297.

Gane, M. (Ed.) (1993). Baudrillard Live: Selected Interviews. London/New York: Routledge.

González, J. (2002). El comercio informal, situación y problemática: respuestas y propuestas. México: Castillo.

Habermas, J. (1989). La transformación estructural de la esfera pública: una investigación sobre una categoría de la sociedad burguesa. Cambridge, Massachusetts: The MIT Press.

Harvey, D. (1989). The Condition of Postmodernity: an Enquiry into the Origins of Cultural Change. London: Blackwell Publishing.

HSLP (2007). Plan Parcial de Conservación del Centro Histórico, municipio de San Luis Potosí. San Luis Potosí, México: H. Ayuntamiento de San Luis Potosí.
Instituto Nacional de Antropología e Historia (INAH) (2002). El patrimonio de México y su valor universal. Lista indicativa. México: INAH.

----- (1990): Decreto de Zona de Monumentos Históricos de la ciudad de San Luis Potosí. San Luis Potosí, México: INAH.

Konopásek, Z. (2008). Making Thinking Visible with Atlas.ti: Computer Assisted Qualitative Analysis as Textual Practices. Forum: Qualitative Social Research, 9(2).

Lefebvre, H. (1976). Espacio y política: el derecho a la ciudad II. Barcelona: Península.

----- (1973). El derecho a la ciudad. Barcelona: Península.

Linares Zarco, J. (2012). La importancia económica de los municipios en el México del siglo XXI. Región y Sociedad, 24(54).

López Gutiérrez, P. (2015). Del comercio informal y los espacios públicos. Nexos.

López Pérez, A. (2017). La movilidad en la zona metropolitana de San Luis Potosí. Tesis de Maestría en Ciencias Ambientales. Programa Multidisciplinario en Ciencias Ambientales. San Luis Potosí, México: UASLP.

Mongín, O. (2006). La condición urbana. La ciudad a la hora de la mundialización (Colección Espacios del Saber, 58). Buenos Aires: Paidós.

Morán de la Rosa, C. (2015). En el contexto fabril del barrio de San Cristóbal del Montecillo de la ciudad de SLP: la Potosina Electric Co. En: J. Villar Rubio, \& E. de X. de Anda A. (Eds.), La ciudad industrial del siglo $x x$ en Latinoamérica: urbanismo y conjunto de vivienda para obreros asociados a los proyectos industria-

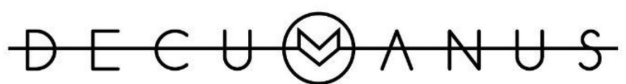

REVISTA INTERDISCIPLINARIA SOBRE ESTUDIOS URBANOS
Núm. 2. Vol. 2. Octubre 2016-Octubre 2017. 
les durante el periodo 1920-1960. México: UASLP/Icomos: 232-242.

Moreno Mata, A. (2017). Urban Sprawl, Environmental Justice, and Equity in Access to Green Spaces in the Metropolitan Area of San Luis Potosí, Mexico. Ponencia presentada en el Symposium SDR México, San Luis Potosí, México. Agenda Ambiental de la UASLP-Manchester University.

----- (2015). Transformación industrial, vivienda para obreros y obsolescencia urbana en el Centro Histórico de San Luis Potosí. Una estrategia para promover la recuperación de espacios antiguos e integrarlos al modelo de Ciudad Compacta. En: J. Villar Rubio, \& E. de X. de Anda A. (Eds.), La ciudad industrial del siglo $x x$ en Latinoamérica: urbanismo y conjunto de vivienda para obreros asociados a los proyectos industriales durante el periodo 1920-1960. México: UASLP/Icomos: 134-163.

----- (2010). Utopía y reconceptualización del modelo urbano mexicano. Enfoques alternativos en el estudio de la centralidad y las "nuevas centralidades": el caso de la zona metropolitana de San Luis Potosí. DADU, Revista de Arquitectura, Diseño y Urbanismo, 7: 180-195.

Organización Internacional del Trabajo (OIT) (1991). The Dilemma of the Informal Sector. Ginebra: OIT.

Portes, A., Roberts, B. R., \& Grimson, A. (Eds.). (2005). Ciudades latinoamericanas: un análisis comparativo en el umbral del nuevo siglo. México: Porrúa.

Ramírez Kuri, P. (2015). Espacio público, ¿espacio de todos? Reflexiones desde la Ciudad de México. Revista Mexicana de Sociología, 77(1): 7-36.
----- (2015). Las disputas por la ciudad, espacio social y espacio público en contextos urbanos de Latinoamérica y Europa. México: Porrúa.

Schjetnan, M. (2008). Principios de diseño urbano ambiental. México: Autor-Editor.

Secretaría de Desarrollo Social (Sedesol) (2010). Documento diagnóstico de rescate de espacios públicos. México: Sedesol.

Sennett, R. (2011). El declive del hombre público. Barcelona: Anagrama.

Valdivieso, N. (2003). Modernización del comercio informal en el Centro Histórico de Quito. Quito: Flacso Sede Ecuador.

Veleda da Silva, S. (2001). Trabajo informal en América Latina: el comercio callejero. Revista Bibliográfica de Geografia y Ciencias Sociales, 317.

Zukin, S. (1995). Las culturas de las ciudades. Oxford: Blackwell.

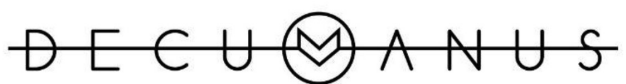

REVISTA INTERDISCIPLINARIA SOBRE ESTUDIOS URBANOS 